\title{
Contribuições de um planejamento conjunto entre as modalidades presencial e a distância na constituição de uma disciplina de prática de ensino de física
}

João Ricardo Neves da Silva iricardo.fisica@unifei.edu.br

0000-0003-1311-0199

Universidade Federal de Itajubá, Itajubá

Minas Gerais, Brasil.

Agenor Pina da Silva

agenor@unifei.edu.br

Universidade Federal de Itajubá, Itajubá,

Minas Gerais, Brasil.

\section{Camila Cardoso Moreira} mila cardoso.fisica@yahoo.com.br 0000-0003-1118-0687

Universidade Estadual Paulista, Bauru, São Paulo, Brasil.

Joaquim Francisco Pereira jrancisco.fisica@yahoo.com.br Universidade Federal de Itajubá, Itajubá, Minas Gerais, Brasil.

\section{RESUMO}

Apresentamos e discutimos as possibilidades formativas advindas de uma relação planejada na construção de uma disciplina de Prática de Ensino de Física em dois cursos de licenciatura em Física nas modalidades presencial e a distância. A partir da análise dos planejamentos conjuntos de dois professores e dos trabalhos e atividades construídas pelos alunos dessas disciplinas, foi possível apresentar uma sistematização de características importantes referentes tanto aos aspectos da formação do professor de Física quanto às possibilidades do planejamento conjunto entre professores de uma mesma disciplina. As análises mostram um distanciamento inicial entre as formas de abordagem dos conteúdos na disciplina nas duas modalidades de Licenciatura em Física e, partindo disso, traçamos um caminho que vise à aproximação dos conteúdos e metodologias, abrindo a possibilidade de discussão sobre as potencialidades do planejamento conjunto de disciplinas nas licenciaturas.
\end{abstract}

PALAVRAS-CHAVE: Planejamento Conjunto. Licenciatura em Física. Licenciatura em Física a Distância. Prática de Ensino de Física. 


\section{INTRODUÇÃO: SOBRE A NECESSIDADE DE PARCERIAS NA CONSTITUIÇÃO DAS LICENCIATURAS EM FÍSICA NA MODALIDADE EAD}

A pesquisa aqui apresentada se realiza no contexto das atuais discussões acerca da ascensão dos cursos de licenciaturas na modalidade de Educação a Distância (EaD) e da necessidade proeminente de fundamentação teórica e de pesquisas relacionadas às especificidades desses cursos. Segundo Cunha, "para a EaD ainda se faz necessário o desenvolvimento de didática, ferramentas de ensino e modelos pedagógicos adequados à modalidade, e à realidade brasileira" (2006, p. 152).

No que se refere à constituição de cursos de licenciatura em Física na modalidade EaD, há uma série de especificidades que necessitam ser estudadas separadamente no intento de elucidar como a organização desses cursos pode caminhar em direção a aspectos cada vez mais formativos na qualificação dos futuros professores. A articulação dos estágios, o ensino dos conteúdos específicos, a formação dos docentes que atuam nesses cursos para esta atuação, entre tantos outros, são exemplos de pontualidades pertinentes na constante compreensão do processo formativo na EaD. Nesse sentido, Fernandes, Quartieiro e Angotti (2011, p. 288) argumentam que dois questionamentos surgem aqui: o ensino a distância pode ser a resposta para a necessária expansão do acesso ao ensino superior, de forma a suprir a carência de docentes no Brasil? É possível nessa modalidade de educação ter uma formação de qualidade?

De acordo com Souza (2009), as ações e pesquisas de busca por metodologias de avaliação coerentes e abrangentes voltadas para a EaD têm se preocupado com questões tais como as cargas horárias, ementas das disciplinas e duração dos cursos, e têm, inclusive, encontrado indicadores de desempenho bastante compatíveis com essas necessidades. Visto que há uma gama considerável e bastante avançada de propostas e estudos na área da constituição legal e burocrática dos cursos de licenciaturas EaD, o argumento desse artigo se envolve com os aspectos mais subjetivos dessa formação, a saber, a atuação dos docentes nas disciplinas voltadas à formação do professor e as possibilidades de constituição das ações formativas nessas disciplinas por meio de planejamento conjunto delas por seus docentes.

A ideia principal aqui é poder trazer à tona uma discussão sobre quais são as contribuições de um planejamento conjunto entre os docentes que lecionam uma disciplina de Prática de Ensino de Física nas modalidades presencial e EaD no que se refere às possibilidades de interações entre essas disciplinas e às produções realizadas por esses licenciandos?

Nesse intento, cabe-nos compreender brevemente o que entendemos por planejamento conjunto e interação entre as disciplinas.

\section{AS POSSIBILIDADES TEÓRICAS DO PLANEJAMENTO CONJUNTO NA CONSTRUÇÃO DE CONHECIMENTO SOBRE AS DISCIPLINAS.}

$\mathrm{Na}$ intenção de estudar as possibilidades advindas de um planejamento conjunto de uma mesma disciplina por seus docentes, é pertinente compreender como os planejamentos conjuntos têm sido objeto de estudos na área de ensino de ciências e, a partir disso, traçarmos as potencialidades desse tipo de interação 
entre docentes no trabalho de elaboração das disciplinas. Sendo assim, apresentamos nesse capítulo a fundamentação teórica de um processo de criação de contextos comunicativos explorando a Teoria do Agir Comunicativo (TAC) (HABERMAS, 2012) e elucidando os conceitos dentro dessa teoria e que se tornam pertinentes na compreensão de como esse agir comunicativo faz-se necessário no processo de mudança dos contextos apresentados e em um processo de formação de docentes da licenciatura em Física.

Para tanto, nos pautamos nos referenciais que versam sobre a interação entre sujeitos na busca por entendimentos, em especial as contribuições de Jürgen Habermas para a discussão dos conceitos de pretensões de validade e coordenação de ações (HABERMAS, 2012), importantes na compreensão desse processo pontual de planejamento conjunto. Nesses termos, pensamos ser possível falar em um ambiente de grupo pautado em referenciais comunicativos quando se pode intentar o que Habermas acredita ser um debate comunicativo de pretensões de validade voltado a um agir coordenado.

Pretensões de validade são as expressões manifestadas por meio de exteriorizações reconhecíveis e acessíveis à análise racional, ou seja, quando um falante que pretende uma ação comunicativa levanta uma pretensão de validade, ele deve se posicionar de forma que sua asserção possa ser racionalmente analisada pelo grupo por meio dos argumentos. (HABERMAS, 2012). As pretensões de validade emitidas podem ter características e funções diferentes dentro da tentativa de entendimento, sendo elas dos seguintes tipos: Descritivas, Normativas, Avaliativas e Explicativas. Esta diferenciação determina a forma como elas serão validadas e questionadas pelos ouvintes. Habermas explica tais diferenças basicamente como

\footnotetext{
Uma análise das formas do enunciado sob um enfoque semântico faz chegar aos mesmos modos de ser. Sentenças descritivas, que em sentido amplo, servem à constatação dos fatos, podem ser afirmadas ou negadas sob o aspecto da verdade de uma proposição; sentenças normativas (ou obrigacionais), que servem à justificação das ações, sob o aspecto da correção (ou da justeza) de um modo de agir; sentenças avaliativas (ou juízos de valor), que se prestam à valoração de algo, sob o aspecto da adequação dos padrões valorativos (ou sob o aspecto do que é bom); e explicações, que servem para esclarecer operações como falar, classificar, fazer cálculos, deduzir, julgar, etc., sob o aspecto da compreensibilidade ou boa formulação das expressões simbólicas. (HABERMAS, 2012, p. 85)
}

Igualmente importante dentro dos nossos recortes da teoria habermasiana para esse trabalho é o conceito de coordenação de ações, descrito pelo referencial como sendo a seguir:

Necessidade de agir coordenado gera na sociedade uma determinada demanda de comunicação; e essa demanda precisa ser atendida quando, para cumprir o propósito de satisfazer essa carência, é obrigatoriamente possível uma coordenação efetiva de ações (HABERMAS, 2012, p. 477). 
A proposição do termo coordenação de ações (HABERMAS, 2012) se fundamenta nas leituras de Habermas sobre a teoria da ação, de Weber (1979). O primeiro autor apresenta o modelo de ação de Weber e o interpreta como baseado na noção de sujeito individual e que agem uns sobre os outros, de maneira teleológica e que tem por intenção fazer com que os outros compreendam o que o sujeito tem em mente, sem a possibilidade de intersubjetivação dos sentidos, como no agir comunicativo. Para Habermas,

A necessidade de agir coordenado gera na sociedade uma determinada demanda de comunicação; e essa demanda precisa ser atendida quando, para cumprir o propósito de satisfazer essa carência, é obrigatoriamente possível uma coordenação efetiva de ações (HABERMAS, 2012, p. 477).

Ou seja, a necessidade de agir coordenado é consequência da necessidade proeminente de comunicação de qualidade da sociedade. Nos princípios da TAC (HABERMAS, 2012), então, a coordenação de ações se apresenta como um dos elementos da busca por entendimentos e consensos entre pessoas que planejam em conjunto (NEVES da SILVA, 2014). Essa concepção por muito também afetou a formação de docentes, aos quais cabia necessariamente a função de aplicador de currículos. Isso favorecia a disseminação de um modelo de formação docente técnico, segundo o qual "as proposições educativas são tratadas como um conjunto de meios destinados a uma finalidade definida" (CARR e KEMMIS, 1988, p. 52).

Na premissa de desenvolvimento de um ambiente no qual há uma "equidade de oportunidades de fala", o "respeito à opinião dos outros participantes" e o "debate aberto e democrático" (HABERMAS, 2012), (MÜHL, 2003), levando em conta a discussão das preocupações temáticas dos participantes com revisão constante do estado das coisas, suscitamos então que os docentes em discussão comecem a se posicionar como um grupo único e, aos poucos, exporem abertamente suas concepções e suas práticas de aula, colocando em dúvida seus próprios métodos e se questionando sobre a validade da forma como conduzem suas disciplinas em comparação com um projeto elaborado em conjunto.

Com relação a estes aspectos, a principal contribuição desta pesquisa está na possibilidade de desenvolvimento do que chamamos de Grupo de Planejamento Conjunto (GPC) das disciplinas em questão. Nesse sentido, o que entendemos como um GPC está relacionado à possibilidade de desenvolvimento de coordenações de ações pelos participantes do grupo.

Ainda, ressaltamos que a concretização de ideologias teóricas sobre a formação de professores de Física passa pelo fato dos docentes que lecionam as disciplinas na licenciatura estarem ou não concatenados em uma perspectiva de estudo e planejamento dialógico das disciplinas, buscando a reflexão e a ação nas suas práticas que sejam condizentes com as necessidades formativas de cada curso. A possibilidade de Planejamento Conjunto entre docentes de disciplinas é o caminho formativo para a constituição de interação entre as disciplinas, como expresso no trabalho de Neves da Silva (2014): 
Ao tomar a interação comunicativa como princípio para a constituição de um processo formativo dos professores que lecionam na licenciatura, podese entender que as construções conjuntas empreendidas pelos docentes e os momentos de tematização da prática, assim como as ações efetivadas, mostram possibilidades reais de continuação deste GPC e, principalmente, mostram as mudanças nas concepções dos participantes sobre o papel das disciplinas específicas na licenciatura em Física (NEVES da SILVA, 2014, p. 104).

Pesquisas tais como a de Neves da Silva (2014), Orquiza de Carvalho (2005), Bortoletto (2013) e Freitas (2008) elucidam as possibilidades da constituição de grupos entre professores na formação de entendimentos sobre aspectos teóricos e pedagógicos de suas próprias atuações e a partir destes referenciais desenvolvemos a análise do já citado processo de planejamento conjunto entre os docentes da disciplina de Prática de Ensino de Física III nas modalidades presencial e a distância de um curso de Licenciatura em Física.

Desta maneira, os questionamentos mais específicos que conduzem esta pesquisa podem ser apontados como:

- Quais as contribuições decorrentes de um planejamento conjunto de uma disciplina de Prática de Ensino de Física nas modalidades presencial e a distância?

- Quais os efeitos de uma abordagem planejada em conjunto pelos docentes nas construções conceituais de alunos dos cursos de licenciatura em Física presencial e EaD sobre o tema "Resolução de Problemas"?

\section{METODOLOGIA: O PLANEJAMENTO CONJUNTO DE ATIVIDADES NA RELAÇÃO PRESENCIAL-EAD}

A principal etapa constituinte desse trabalho é o planejamento das disciplinas a partir de um GPC formado por dois docentes que lecionam as disciplinas de Prática de Ensino de Física III, um na modalidade à distância e outro na modalidade presencial do curso de Licenciatura em Física. Tal planejamento se deu a partir das ideias anteriormente apresentadas, ou seja, partiu de uma ideia de compreensão mútua das especificidades e das possibilidades de integração entre as atividades realizadas em ambos os cursos. Nesse sentido, os docentes planejaram toda a estrutura da disciplina, os referenciais, as leituras, as atividades e as abordagens em conjunto, comparando e levando em consideração as diferentes formas de ação de cada uma das modalidades.

Os dois professores se reuniram semanalmente para desenvolver discussões e estudos sobre os temas das aulas da semana e a forma de abordagem para cada modalidade. Os planejamentos e os estudos conjuntos foram registrados para, juntamente com as produções dos licenciandos em atuação nessas disciplinas, comporem o corpus de análise dessa pesquisa.

A ênfase nesta etapa foi na reflexão sobre as aproximações e convergências necessárias que deveriam ser utilizadas na constituição das aulas. É importante ressaltar que não se trata do planejamento de atividades a serem realizadas da mesma forma para os dois cursos, mas de uma busca por elementos que são especificamente necessários em cada uma das modalidades que poderiam ser desenvolvidos em conjunto pelos docentes, no intento de atender a um mesmo 
conjunto de princípios formativos necessários à formação dos futuros professores na disciplina em questão.

As disciplinas denominadas Prática de Ensino de Física em ambos os cursos foram elaboradas com o intuito de trabalhar conceitos estudados nas disciplinas de Física Geral juntamente com temas relacionados aos conhecimentos próprios do Ensino de Física. Em particular, nas disciplinas discutidas neste trabalho, que possuem uma carga horária semestral de 64 horas-aula, o tema específico em análise é a Mecânica Newtoniana.

As aulas na modalidade EaD são disponibilizadas duas vezes por semana no ambiente virtual de aprendizagem (AVA) utilizado pela universidade. Em geral, na primeira aula da semana é apresentado o assunto que será - ou está sendo estudado e na segunda é proposta alguma atividade avaliativa relacionada com a aula anteriormente apresentada. As soluções apresentadas pelos alunos para essas atividades avaliativas são disponibilizadas utilizando o portfólio individual, ferramenta do AVA.

Já na modalidade presencial de curso, a disciplina conta com uma carga horária de 04 horas-aula semanais e segue os modelos normalmente utilizados para as aulas, com atividades de prática de ensino a partir das teorias em estudo sendo realizadas em sala de aula. No Quadro 1 é apresentada a ementa de conteúdos, que é a mesma para ambas as modalidades de curso.

Quadro 1: Conteúdo programático da disciplina "Prática de Ensino de Física III" em ambas as modalidades de curso.

\begin{tabular}{|l|l|}
\hline $\begin{array}{l}\text { Conteúdo Específico de } \\
\text { Física }\end{array}$ & $\begin{array}{l}\text { Conteúdo disciplinar da área de Ensino de } \\
\text { Física }\end{array}$ \\
\hline \multirow{3}{*}{ Mecânica Newtoniana } & Concepções Alternativas \\
\cline { 2 - 2 } & Transposição Didática \\
\cline { 2 - 2 } & $\begin{array}{l}\text { O papel da Resolução de Problemas no } \\
\text { Ensino de Física }\end{array}$ \\
\hline
\end{tabular}

Assim, o propósito das disciplinas é apresentar elementos teóricos sobre o ensino e a aprendizagem desenvolvidos juntamente aos tópicos específicos da mecânica newtoniana.

A seguir, nas compreensões e sistematizações dos resultados, são apresentados os resultados do planejamento conjunto dos professores e as atividades desenvolvidas por eles durante o semestre letivo, além das análises dos trabalhos produzidos pelos licenciandos, buscando compreender de que forma este planejamento conjunto afeta as ações de aula organizadas pelos alunos, futuros professores, que cursam essa disciplina

\section{AS POSSIBILIDADES DO PLANEJAMENTO CONJUNTO DE DISCIPLINAS: SISTEMATIZAÇÃO E ANÁLISE DOS DADOS}


A partir das iniciativas e dos referenciais anteriormente descritos, apresentamos aqui a sistematização e compreensão das informações visando explicitar os momentos de planejamento conjunto, as ações nas disciplinas geradas por esses planejamentos e as construções realizadas pelos alunos durante as aulas planejadas aplicadas. Ressaltando que o objetivo principal deste artigo é elucidar os resultados do processo de planejamento conjunto das disciplinas, apresentamos a seguir trechos escolhidos das análises que evidenciem como foram realizadas as compreensões sobre o processo de planejamento entre os docentes.

Baseados nos conceitos habermasianos de pretensões de validade e coordenação de ações, os docentes buscaram desenvolver uma sequencia de reuniões de planejamento nas quais eram apresentados sequencialmente os temas e os conteúdos de cada aula semanal e então debatidas as possibilidades de interação entre esses conteúdos visando uma formação de habilidades comuns dadas as diferenças de abordagens de cada modalidade. No Quadro 2 são apresentados dois exemplos de análise desses planejamentos, visando elucidar como estes foram analisados na compreensão deste artigo.

Quadro 2: Sistematização das análises das interações entre os docentes no planejamento conjunto

\begin{tabular}{|c|c|c|}
\hline Ato de fala & Características & Sínteses \\
\hline $\begin{array}{l}\text { "Olha essa tabela que } \\
\text { eu fiz. Tem uma lista de } \\
\text { coisas que eu acho que } \\
\text { é importante que os } \\
\text { alunos façam na } \\
\text { disciplina, as coisas que } \\
\text { eu acho que a disciplina } \\
\text { deve solicitar deles, pra } \\
\text { que eles façam, } \\
\text { entende?" (Docente 1) }\end{array}$ & $\begin{array}{l}\text { Sistematização e } \\
\text { organização das } \\
\text { explicações e requisição } \\
\text { de inteligibilidade }\end{array}$ & $\begin{array}{l}\text { O docente } 1 \text { apresenta } \\
\text { uma organização inicial } \\
\text { em forma de tabela } \\
\text { para iniciar o } \\
\text { planejamento conjunto } \\
\text { do tópico, usa frases } \\
\text { explicativas e requisita } \\
\text { do docente } 2 \\
\text { demonstração de } \\
\text { compreensão da } \\
\text { explicação. Todos } \\
\text { elementos da } \\
\text { argumentação são } \\
\text { voltados ao } \\
\text { entendimento. }\end{array}$ \\
\hline \multirow{3}{*}{$\begin{array}{l}\text { "Sim... sim... Mas daí } \\
\text { quando você coloca aqui } \\
\text { que o aluno deve saber } \\
\text { elaborar e desenvolver } \\
\text { aulas utilizando a } \\
\text { transposição didática, } \\
\text { como vamos fazer isso } \\
\text { no EaD? (Docente 2) }\end{array}$} & $\begin{array}{l}\text { Compreensão da } \\
\text { informação fornecida } \\
\text { pelo docente } 1\end{array}$ & \multirow{3}{*}{$\begin{array}{l}\text { O docente } 2 \text { demonstra } \\
\text { compreensão da } \\
\text { sistematização } \\
\text { apresentada e solicita } \\
\text { explicações sobre mais } \\
\text { um aspecto da } \\
\text { organização da aula. }\end{array}$} \\
\hline & $\begin{array}{l}\text { Requisição de } \\
\text { inteligibilidade sobre a } \\
\text { abordagem no EaD }\end{array}$ & \\
\hline & $\begin{array}{l}\text { Levantamento de } \\
\text { pretensão de validade } \\
\text { expressiva }\end{array}$ & \\
\hline
\end{tabular}


"Então...eu acho que isso depende do que a gente vai pedir que os alunos façam no EaD, por exemplo. Vamos supor que a gente coloque lá no AVA textos de revista científica e algum exemplo de aula preparado a partir dele. Daí solicitamos que os alunos elaborem planos de aula e "power points" dessas aulas. Acho que e uma boa maneira de praticar em forma de aula." (Docente 1)

"Entendi...Então nessa parte você vai pedir que os seus alunos

(presencial) apresentem uma aula elaborada a partir de um texto de divulgação e eu vou lançar os exemplos de aula com esses textos e solicitar deles uma apresentação em "power point". Daí você me ajuda a corrigir esses power points e ver o que os seus apresentaram." (Docente 2)

"Sim... Mas eu vou dar aula pra eles antes, apresentar o texto de transposição (didática) e exemplo de aula com esses textos. Acho que vou utilizar um sobre as tsunamis e ondas... Mas OK...É bem isso mesmo...Porque a gente está fazendo a mesma sequencia..." (Docente 1)
Pretensão de validade explicativa. Solicitação de aceitação do argumento.
O docente 1 fornece mais explicações de sua apresentação e expõe uma pretensão de validade para a aceitação ou não do docente 2. Esse movimento representa a busca por entendimento sobre este planejamento conjunto.
Expressão de compreensão da explicação.

Apresentação do estado do processo de entendimento.
O docente 1 demonstra compreensão e faz um resumo da proposta construída pelos dois, no intento de facilitar a compreensão dos elementos desse planejamento.
Entendimento sobre os procedimentos de uma aula. Pretensão de validade avaliativa

\section{Acordo sobre a}

estrutura da abordagem neste tópico.

Representação de entendimento a partir da construção conjunta. 

conjunto

\begin{tabular}{|c|c|c|}
\hline Ato de fala & Características & Sínteses \\
\hline $\begin{array}{l}\text { "Agora, essa questão } \\
\text { do modelo de } \\
\text { resolução de } \\
\text { problemas. Tem as } \\
\text { regras de elaboração } \\
\text { de problemas abertos } \\
\text { do texto que eles } \\
\text { leram, a nossa } \\
\text { resolução que eu vou } \\
\text { postar no AvA, será } \\
\text { que é bom explicitar as } \\
\text { etapas da resolução?" } \\
\text { (Docente 2) }\end{array}$ & $\begin{array}{l}\text { Pretensão de validade } \\
\text { avaliativa. Solicitação } \\
\text { de análise do } \\
\text { planejamento por } \\
\text { parte do docente } 2 \text {. }\end{array}$ & $\begin{array}{l}\text { O docente } 1 \text { apresenta } \\
\text { sua explicação } \\
\text { acompanhada de uma } \\
\text { pretensão uma } \\
\text { planejamento, } \\
\text { solicitando do } \\
\text { consideração } \\
\text { docente } 2 \text { sobre ela. }\end{array}$ \\
\hline $\begin{array}{l}\text { "Eu acho que sim, que } \\
\text { a gente deve construir } \\
\text { uma resolução de } \\
\text { problemas e ir } \\
\text { apontado em cada } \\
\text { etapa a exploração das } \\
\text { possibilidades, recolha } \\
\text { de dados, análise dos } \\
\text { resultados e outras } \\
\text { possibilidades de } \\
\text { resultados. Enfim, eu } \\
\text { acho que a gente deve } \\
\text { fazer um modelo de } \\
\text { resolução com essas } \\
\text { indicações, pra ligar } \\
\text { com a leitura e porque } \\
\text { eles devem ter isso } \\
\text { como orientação para } \\
\text { elaborar o problema } \\
\text { deles né?" (Docente 1) }\end{array}$ & $\begin{array}{l}\text { Pretensão de validade } \\
\text { normativa. Uso de } \\
\text { exemplos explicativos. } \\
\text { Solicitação de } \\
\text { aprovação por parte do } \\
\text { docente } 1\end{array}$ & $\begin{array}{l}\text { Ao apresentar sua } \\
\text { ideia de ação na aula } \\
\text { como uma norma, o } \\
\text { docente 1estabelece } \\
\text { uma possibilidade de } \\
\text { avaliação da proposta. } \\
\text { Assim, abre caminho } \\
\text { para o debate livre } \\
\text { sobre essa proposta de } \\
\text { ação. }\end{array}$ \\
\hline
\end{tabular}




\begin{tabular}{|c|c|c|}
\hline $\begin{array}{l}\text { "Então vamos fazer } \\
\text { assim, essa semana eu } \\
\text { vou abordar com eles } \\
\text { na aula (presencial) a } \\
\text { resoluçãor desse } \\
\text { problemar que } \\
\text { elaboramos aqui. } \\
\text { Resolvo com detalhes } \\
\text { com eles e vou } \\
\text { explicitando as etapas } \\
\text { da resolução } \\
\text { relembrando a leitura. } \\
\text { Daí você posta no } \\
\text { ambiente o exemplode } \\
\text { resolução } \\
\text { problemas. E depois } \\
\text { solicitamos que eles } \\
\text { elaborem o problema } \\
\text { deles com a resolução } \\
\text { e apresentem. No meu } \\
\text { caso pessoalmente e } \\
\text { no EaD em forma de } \\
\text { elaboração em slides." } \\
\text { (Docente } 1 \text { ) }\end{array}$ & $\begin{array}{l}\text { Revisão do estado das } \\
\text { coisas. Pretensão de } \\
\text { validade normativa. }\end{array}$ & $\begin{array}{l}\text { Os docentes organizam } \\
\text { conjuntamente a ação } \\
\text { individual de cada um } \\
\text { eles em suas disciplinas } \\
\text { a partir do resumo do } \\
\text { planejamento } \\
\text { executado pelo } \\
\text { docente } 1 .\end{array}$ \\
\hline $\begin{array}{l}\text { "Sim, ok...Mas eu acho } \\
\text { que a gente tem que } \\
\text { melhorar muito esse } \\
\text { exemplo escrito que eu } \\
\text { vou postar no EaD. A } \\
\text { gente podia ler e ir } \\
\text { acrescentando mais } \\
\text { explicações e detalhes. } \\
\text { Eles não terão a gente } \\
\text { pra ir tirando as } \\
\text { duvidas, né?" (Docente } \\
\text { 2) }\end{array}$ & $\begin{array}{l}\text { Demonstração de } \\
\text { compreensão do } \\
\text { planejamento } \\
\text { elaborado. } \\
\text { Reapresentação da } \\
\text { construção conjunta. }\end{array}$ & $\begin{array}{ll}\text { Consenso sobre } & \text { a } \\
\text { etapa anterior } & \mathrm{e} \\
\text { apontamento } & \text { de } \\
\text { melhoras } & \text { na } \\
\text { elaboração } & \end{array}$ \\
\hline
\end{tabular}


O Quadros 2 e 3 mostram como foram realizadas as reuniões de planejamento das disciplinas e a forma como os entendimentos eram buscados pelos docentes envolvidos no processo. Aqui é possível observar a busca por entendimento sobre os elementos que poderiam constituir as duas disciplinas em conjunto. Atentamos para o fato de que este tipo de planejamento pode resultar na possibilidade de desenvolvimento de característica de ação comunicativa, como expresso. Assim, o processo de constituição do planejamento conjunto se deu entre os dois docentes em um ambiente de ação comunicativa, no qual os elementos que deveriam fazer parte das ações de ambos nas disciplinas foram negociados até que se alcançasse o entendimento.

Ressaltamos o fato de que os Quadros 2 e 3 são exemplos de como foi realizado o processo de análise das interações entre os docentes, sendo que muitos outros episódios do processo de planejamento conjunto foram registrados e analisados na mesma perspectiva.

A partir desse planejamento conjunto, foi possível construir uma estrutura de interação planejada entre as disciplinas, buscando relações e formas de atingir princípios comuns na formação dos futuros professores nessas disciplinas. No Quadro 4 são mostradas as aulas planejadas em conjunto sobre o tópico "O papel da Resolução de Problemas no Ensino de Física", sobre o qual voltaremos nossa atenção neste artigo.

Quadro 4: Planejamento conjunto das atividades de aula da disciplina "Prática de Ensino III" em ambas as modalidades de curso.

\begin{tabular}{|c|c|c|c|}
\hline Aula & $\begin{array}{c}\text { Abordagem da } \\
\text { aula }\end{array}$ & Atividade Solicitada & Objetivo \\
\hline EaD & $\begin{array}{l}\text { Leitura do artigo } \\
\text { "Resolução de } \\
\text { problemas no } \\
\text { ensino de física } \\
\text { baseado numa } \\
\text { abordagem } \\
\text { investigativa", } \\
\text { de Clement, }\end{array}$ & $\begin{array}{l}\text { Pensando em um } \\
\text { Ensino de Física } \\
\text { fundamentado } \\
\text { na problematização dos } \\
\text { conhecimentos físicos, } \\
\text { os alunos devem } \\
\text { escrever um texto de } \\
\text { opinião com, no } \\
\text { mínimo, } 10 \text { linhas. }\end{array}$ & $\begin{array}{l}\text { objetivo da } \\
\text { primeira leitura, } \\
\text { igual para ambos os } \\
\text { cursos, é iniciar uma } \\
\text { discussão sobre o } \\
\text { papel da } \\
\text { problematização no }\end{array}$ \\
\hline Presencial & $\begin{array}{l}\text { Terrazan e } \\
\text { Nascimento. }\end{array}$ & $\begin{array}{l}\text { Discussão, em sala de } \\
\text { aula, sobre o conceito } \\
\text { de problematizações } \\
\text { com exemplos. }\end{array}$ & Ensino de Física. \\
\hline
\end{tabular}




\begin{tabular}{|c|c|c|c|}
\hline EaD & $\begin{array}{l}\text { Fazer a leitura } \\
\text { do texto "Sobre } \\
\text { a resolução de } \\
\text { problemas no } \\
\text { Ensino de } \\
\text { Física" de } \\
\text { autoria de Luiz } \\
\text { O.Q. Peduzzi }\end{array}$ & $\begin{array}{l}\text { É apresentada a } \\
\text { solução de um } \\
\text { problema relacionado à } \\
\text { Mecânica e proposta a } \\
\text { resolução de um } \\
\text { problema-teste aos } \\
\text { alunos. } \\
\text { Participação no fórum } \\
\text { no AVA "Resolução de } \\
\text { Problemas" a respeito } \\
\text { da leitura sugerida. }\end{array}$ & $\begin{array}{l}\text { Que os alunos } \\
\text { buscassem, a partir } \\
\text { das etapas } \\
\text { apresentadas na } \\
\text { leitura sugerida, } \\
\text { iniciar a resolução de } \\
\text { um problema } \\
\text { proposto e então } \\
\text { discutissem as } \\
\text { dificuldades } \\
\text { encontradas e as } \\
\text { metodologias } \\
\text { utilizadas no fórum } \\
\text { de discussões. }\end{array}$ \\
\hline Presencial & $\begin{array}{l}\text { Resolução, em } \\
\text { aula, de um } \\
\text { problema- } \\
\text { exemplo, } \\
\text { discutindo com } \\
\text { os alunos as } \\
\text { etapas da } \\
\text { resolução de } \\
\text { problemas } \\
\text { apresentadas no } \\
\text { texto lido } \\
\text { anteriormente }\end{array}$ & $\begin{array}{l}\text { Elaboração de um } \\
\text { problema aberto } \\
\text { resolvido, com a } \\
\text { explicitação de todas as } \\
\text { etapas de resolução } \\
\text { sugeridas pelo texto } \\
\text { lido. }\end{array}$ & \begin{tabular}{lr}
\multicolumn{2}{l}{ Os alunos iniciarem o } \\
processo de \\
elaboração de \\
problemas abertos \\
seguindo da \\
recomendações da \\
leitura sugerida.
\end{tabular} \\
\hline
\end{tabular}




\begin{tabular}{|c|c|c|c|}
\hline EaD & $\begin{array}{l}\text { Solicitar a leitura } \\
\text { do artigo "Ensino } \\
\text { de Física: da } \\
\text { resolução de } \\
\text { problemas à } \\
\text { formulação de } \\
\text { questões" de } \\
\text { André Bessadas } \\
\text { Penna-Firme. } \\
\text { Disponibilizar } \\
\text { um problema } \\
\text { aberto resolvido } \\
\text { com explicações } \\
\text { escritas para os } \\
\text { alunos }\end{array}$ & $\begin{array}{l}\text { Fazer uma resenha do } \\
\text { artigo "Ensino de Física: } \\
\text { da resolução de } \\
\text { problemas à formulação } \\
\text { de questões" de André } \\
\text { Bessadas Penna-Firme. } \\
\text { Ler a resolução do } \\
\text { problema exemplo } \\
\text { disponibilizada no AVA } \\
\text { e realizar uma anotação } \\
\text { em seu diário de bordo. }\end{array}$ & $\begin{array}{l}\text { O objetivo da aula } \\
\text { em ambos os cursos } \\
\text { é que os alunos } \\
\text { possam prosseguir } \\
\text { na compreensão das } \\
\text { características de } \\
\text { uma resolução de } \\
\text { problemas. No EaD, } \\
\text { isto é feito por meio } \\
\text { da leitura de uma } \\
\text { resolução de } \\
\text { problemas e no }\end{array}$ \\
\hline Presencial & $\begin{array}{l}\text { Aula expositiva } \\
\text { sobre tipos de } \\
\text { resolução de } \\
\text { problemas com } \\
\text { exemplos de } \\
\text { problemas } \\
\text { resolvidos por } \\
\text { diversos } \\
\text { métodos }\end{array}$ & $\begin{array}{l}\text { Responder a } \\
\text { questionamentos sobre } \\
\text { aspectos conceituais da } \\
\text { física na elaboração de } \\
\text { problemas abertos }\end{array}$ & $\begin{array}{l}\text { presencial por meio } \\
\text { da resolução de } \\
\text { vários tipos de } \\
\text { problemas pelo } \\
\text { docente. }\end{array}$ \\
\hline EaD & $\begin{array}{l}\text { Discutir com os } \\
\text { alunos os } \\
\text { detalhes dos } \\
\text { problemas } \\
\text { abertos } \\
\text { construídos por } \\
\text { eles }\end{array}$ & $\begin{array}{l}\text { Participar do fórum de } \\
\text { discussão "Tempo } \\
\text { Lógico" e a segunda é } \\
\text { uma reflexão sobre } \\
\text { Problemas e } \\
\text { Problematizações. }\end{array}$ & $\begin{array}{l}\text { O fórum de } \\
\text { discussão, } \\
\text { concatenado com a } \\
\text { leitura sugerida, } \\
\text { pretende que os } \\
\text { alunos possam } \\
\text { apresentar } \\
\begin{array}{l}\text { propostas } \\
\text { resolução de } \\
\text { problemas } \\
\text { fundamentadas nas }\end{array}\end{array}$ \\
\hline
\end{tabular}




\begin{tabular}{|c|c|c|c|}
\hline & & & $\begin{array}{l}\text { questões teóricas } \\
\text { que as envolvem. }\end{array}$ \\
\hline Presencial & $\begin{array}{l}\text { Apresentação, } \\
\text { pelos alunos, da } \\
\text { resolução do } \\
\text { problema } \\
\text { elaborado por } \\
\text { eles mesmos em } \\
\text { sala de aula }\end{array}$ & $\begin{array}{l}\text { Elaborar uma } \\
\text { explicação para a } \\
\text { resolução do problema } \\
\text { proposto e construí-la } \\
\text { em sala de aula para } \\
\text { discussão com os alunos } \\
\text { e os professores. }\end{array}$ & $\begin{array}{l}\text { Com o mesmo } \\
\text { objetivo do EaD, a } \\
\text { possibilidade de os } \\
\text { alunos realizarem a } \\
\text { apresentação de } \\
\text { uma resolução de } \\
\text { problemas proposta } \\
\text { por eles permite a } \\
\text { discussão } \\
\text { construção de } \\
\text { melhoramentos para } \\
\text { estas resoluções em } \\
\text { sala de aula. }\end{array}$ \\
\hline EaD & $\begin{array}{l}\text { Discussão do } \\
\text { texto da } \\
\text { resolução literal } \\
\text { de problemas. } \\
\text { Apresentação e } \\
\text { discussão com os } \\
\text { alunos, no AVA, } \\
\text { os elementos da } \\
\text { construção de } \\
\text { um plano de aula } \\
\text { que envolva } \\
\text { resolução de } \\
\text { problemas }\end{array}$ & $\begin{array}{l}\text { Construção de um plano } \\
\text { de aula com uma } \\
\text { abordagem de } \\
\text { resolução de problemas } \\
\text { e apresentação deste, } \\
\text { em forma de slides, } \\
\text { para todos no AVA. }\end{array}$ & 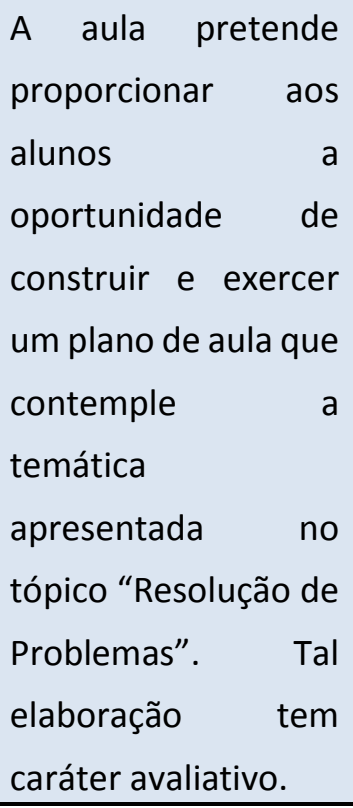 \\
\hline
\end{tabular}




\begin{tabular}{|c|c|c|c|}
\hline Presencial & $\begin{array}{l}\text { Apresentação de } \\
\text { uma aula } \\
\text { completa com } \\
\text { utilização de } \\
\text { uma resolução } \\
\text { de problemas }\end{array}$ & $\begin{array}{lr}\text { Elaboração } & \text { e } \\
\text { apresentação, pelos } \\
\text { alunos, de uma } \\
\text { contendo } & \text { uma } \\
\text { resolução } & \text { de } \\
\text { problemas. } & \end{array}$ & $\begin{array}{l}\text { Desenvolver com os } \\
\text { alunos a habilidade } \\
\text { de explicação oral de } \\
\text { um problema aberto. } \\
\text { Tal elaboração tem } \\
\text { caráter avaliativo. }\end{array}$ \\
\hline
\end{tabular}

O Quadro 4 expressa o resultado do planejamento conjunto realizado pelos docentes em interação, especificamente sobre o tópico "O papel da Resolução de Problemas no Ensino de Física". O que é possível observar nestes trechos é o fato de que as atividades e aulas propostas visam a construção de uma aproximação entre o que é realizado nas duas modalidades de curso. O que é imprescindível ressaltar é que a oportunidade de um planejamento conjunto das disciplinas faz com que os professores se proponham a conhecer as disciplinas um dos outros e a pensar as atividades, leituras, aulas expositivas e trabalhos que são solicitados nessas disciplinas a fim de repensar a sua própria prática.

No caso desta experiência de planejamento conjunto, os dois docentes discutem aula por aula, em uma perspectiva comunicativa, o que deve ser realizado por cada um deles em cada modalidade de curso, a fim de desenvolverem a disciplina com a maior aproximação possível de conteúdos e práticas. Ou seja, a intenção dos docentes com o planejamento conjunto não é a padronização das disciplinas, mas uma uniformidade na formação do professor que cursa a Licenciatura em Física em ambas as modalidades de curso.

A seguir, apresentamos alguns resultados das atividades executadas pelos alunos durante o desenvolvimento do planejamento conjunto em sala de aula, para que seja possível analisar a uniformidade nas ações desses alunos e/ou as possibilidades formativas desse tipo de interação entre os docentes na formação dos licenciandos.

\section{ANÁLISE DAS ATIVIDADES REALIZADAS PELOS LICENCIANDOS NAS DISCIPLINAS PLANEJADAS EM CONJUNTO: INTERPRETAÇÃO COMPLEMENTAR DOS DADOS}

A elaboração de problemas pelos alunos foi aqui analisada com o intuito de compreender como, a partir dos textos e das atividades trabalhados durante as aulas, os problemas foram produzidos por eles. As atividades solicitadas aos alunos se constituem daquelas planejadas em conjunto pelos docentes e essas análises, então, fornecem subsídios para avaliar a pertinência dos planejamentos conjuntos elaborados. São apresentados aqui alguns exemplos de elaborações dos alunos de ambas as disciplinas visando a compreensão da reflexão que se faz sobre elas, mas o corpo de análise compreende todas as atividades e trabalhos solicitados aos alunos durante o andamento das disciplinas.

Os alunos do curso EaD elaboraram problemas abertos tal como recomendado nos textos sugeridos, mas principalmente seguindo o modelo de resolução de problemas apresentado em textos com exemplos. Além disso, foi possível observar que os problemas apresentados por eles são mais fechados que 
abertos, contendo informações numéricas e a determinação de um caminho de resolução, possivelmente também devido à influência dos textos com exemplos que também continham essas características. O Quadro 5 apresenta o enunciado de um problema elaborado por um dos alunos do curso EaD.

Quadro 5: Problema elaborado por um aluno da licenciatura em física EaD

José deseja deslocar uma caixa em uma superfície horizontal. Calcule a força necessária para que ele possa fazer isso em função da energia e da distância.

Os problemas elaborados pelos alunos do curso presencial, em geral, se apresentam com características também presentes nos textos de referência, mas ainda com elementos do cotidiano ou a partir destes elementos. Como pode ser observado no exemplo do Quadro 6, que apresenta um enunciado de problema elaborado por um dos alunos do curso presencial, há um aspecto relevante, que é a inserção de contextos, ou enunciados, com situações cotidianas. Isso pode ser explicado pela oportunidade, dada pela disciplina nesta modalidade, de os alunos discutirem conceitualmente seus problemas elaborados em sala de aula e principalmente de apresentarem o problema, assim como sua resolução, para as considerações dos colegas e do professor.

Quadro 6: Problema elaborado por um aluno da licenciatura em física

Maria estava passeando em um parque de diversões, quando de repente começa a observar o movimento de um carrinho na montanha russa. Ela ficou curiosa com as diferentes posições que o carrinho ocupava e começa a se questionar porque, durante o looping, o carrinho não cai. Assim, qual deve ser a velocidade mínima para que um carrinho não caia em um looping de montanha russa?

Outro elemento analisado foi a construção de explicações dos problemas condizentes com os princípios planejados pelos docentes. Segundo o planejamento apresentado anteriormente, as atividades desenvolvidas nas aulas foram conduzidas de forma que em ambos os cursos se tentasse levar os licenciandos a elaborar e resolver problemas segundo as recomendações dos referenciais teóricos da área. As metodologias seguidas pelos docentes são diferentes e se adequam às modalidades do curso, mas os objetivos das aulas e as competências a serem desenvolvidas nos licenciandos são as mesmas, e planejadas em conjunto. Desse modo, o que se encontrou foram problemas resolvidos seguindo as recomendações dos referenciais abordados em aula, mas com linguagens diferentes, como exemplificado no Quadro 7.

Quadro 7: Exemplo de construção de problema por um aluno do curso presencial.

$1^{\circ}$ : Fazer algum esquema, desenho ou algo do tipo

$2^{\circ}$ : Pensar em hipóteses (por exemplo: sem atrito)

$3^{\circ}$ : Resolver o problema literalmente para depois substituir os valores.

$4^{\circ}$ : Analisar os resultados encontrados (Por exemplo: Aceleração positiva, então o 
Os problemas resolvidos pelos alunos do curso EaD seguem, em geral as etapas sugeridas pelos textos, enquanto no curso presencial as etapas estão observadas, mas "diluídas" durante a resolução dos problemas. Isso evidentemente se deve às abordagens diferenciadas nas duas modalidades de curso, pois enquanto no presencial as discussões sobre os termos e formas de resolução de problemas são reinterpretadas pelo professor, no EaD as recomendações teóricas são lidas diretamente nos referenciais.

Apesar das diferentes formas de abordagem, ainda assim se pode observar que uma gama significativa de alunos em ambas as modalidades de curso apresenta, em suas atividades realizadas, as características planejadas em conjunto pelos docentes para a metodologia de resolução de problemas, de modo que é possível relatar os ganhos do planejamento de disciplinas em conjunto para esses cursos.

Outra situação que exemplifica a compreensão que foi realizada a partir do estudo dos trabalhos realizados pelos alunos é a que trata da proposição de uma elaboração de aula baseada na exploração de concepções alternativas dos estudantes. Após estudarem as possibilidades de uma abordagem que buscasse a exploração dessas concepções e tomarem contato com aulas que exemplificassem essa abordagem, foi solicitado aos licenciandos que elaborassem e executassem um plano de aula voltado à esta prática. Além disso, os licenciandos também elaboraram um mapa conceitual do assunto tratado em seu plano de aula. As elaborações de dois licenciandos, um de cada modalidade do curso são apresentadas e interpretadas a seguir.

\section{Procedimentos:}

- Iniciar as atividades com um questionamento sobre o que é a $3^{\text {a }}$ lei de Newton;

- Promover uma pequena discussão sobre as respostas obtidas pelos alunos;

- Dar exemplos utilizando as gifs que serão anexadas no final da página;

- Questionar os alunos sobre o que é equilíbrio;

- Promover uma segunda discussão sobre as respostas obtidas pelos alunos;

- Fazer uma leitura sobre o texto anexo referente a equilíbrio;

- Promover uma terceira discussão sobre o texto;

- Formalizar o conceito científico sobre ação e reação e equilíbrio de modo a promover uma mudança de perfil conceitual. 


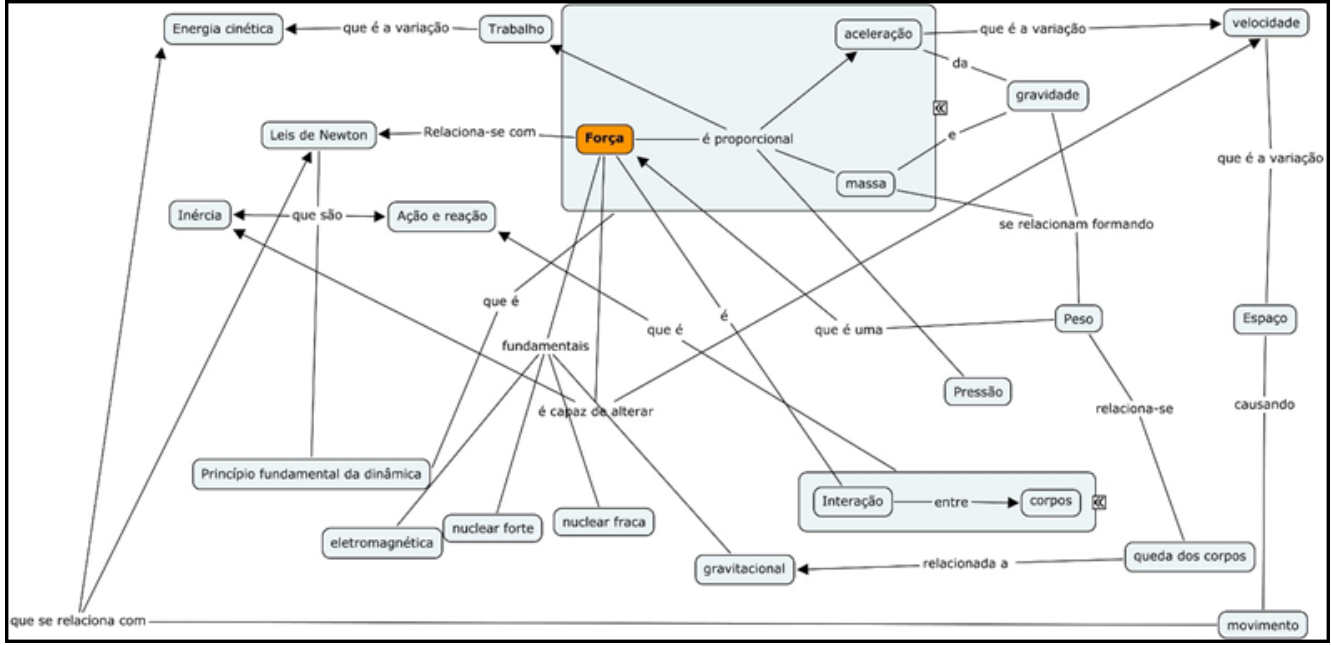

(b)

Figura 1: (a) Exemplo de ordenação das ações de uma aula baseada em exploração de conceitos prévios elaborada por um aluno do curso EaD; (b) Mapa conceitual de um conteúdo de mecânica elaborado no plano de aula do mesmo aluno.

A parte (a) da Figura 1 mostra um trecho do plano de aula elaborado por um dos alunos do curso de licenciatura EaD após o estudo e a prática dos conteúdos de mecânica do Ensino Médio na perspectiva da exploração e reflexão dos conceitos prévios dos estudantes. O que podemos observar dessa elaboração é que ela segue alguns passos que foram trabalhados com os alunos no AVA a partir das leituras sugeridas e das aulas-exemplo postadas no ambiente. $O$ licenciando propõe uma sequência de atividades que vão desde uma forma de identificar os conceitos prévios até uma conclusão sobre os conceitos, passando por momentos de discussão de vários fenômenos que compõem o conteúdo estudado. É possível observar a organização conceitual do licenciando a partir do mapa conceitual, parte (b) da Figura 1, elaborado por ele.

A seguir podemos observar a mesma elaboração realizada por um aluno do curso presencial, como mostrado na Figura 2. 
1a - Para chegar a conhecer as "concepções originais" é necessário que antes de passar os conceitos ou respostas fazer perguntas. Como o exemplo dado pelo próprio texto, perguntar se jogando uma bola para cima quais forças estão agindo sobre a bola, caso haja uma representação intuitiva errônea ela já será exposta e poderá ser trabalhada.

2a - Acho que para encorajar os alunos a descreverem suas ideias é necessário ser receptivo a elas, não só dizer "isso está errado!", mas estender essa suposição até chegar ao erro.

3a-Ser paciente, ir lançando questões a respeito de suas ideias.

$4 \underline{a}$ - É importante a cima de tudo formar pessoas críticas, não apenas pessoas que aceitam o que o professor diz, ou que fiquem com conflitos internos em relação ao que foi exposto com o conceito prévio. A discussão é necessária, e talvez atribuir prós e contras a teorias aceitáveis cientificamente com as intuitivas seja uma boa forma para conduzir essa discussão.

5a - Utilizando novamente um exemplo do texto, digamos que um aluno responda:

- O responsável pela força gravitacional é a pressão atmosférica

O professor no caso pode fazer uma pergunta do tipo:

- Você viu nos jornais a respeito do robô espacial Curiosity em marte?A superfície de marte é muito rarefeita (quase mínima em comparação com a terra) e mesmo assim o robozinho não fica flutuando.

\section{(a)}

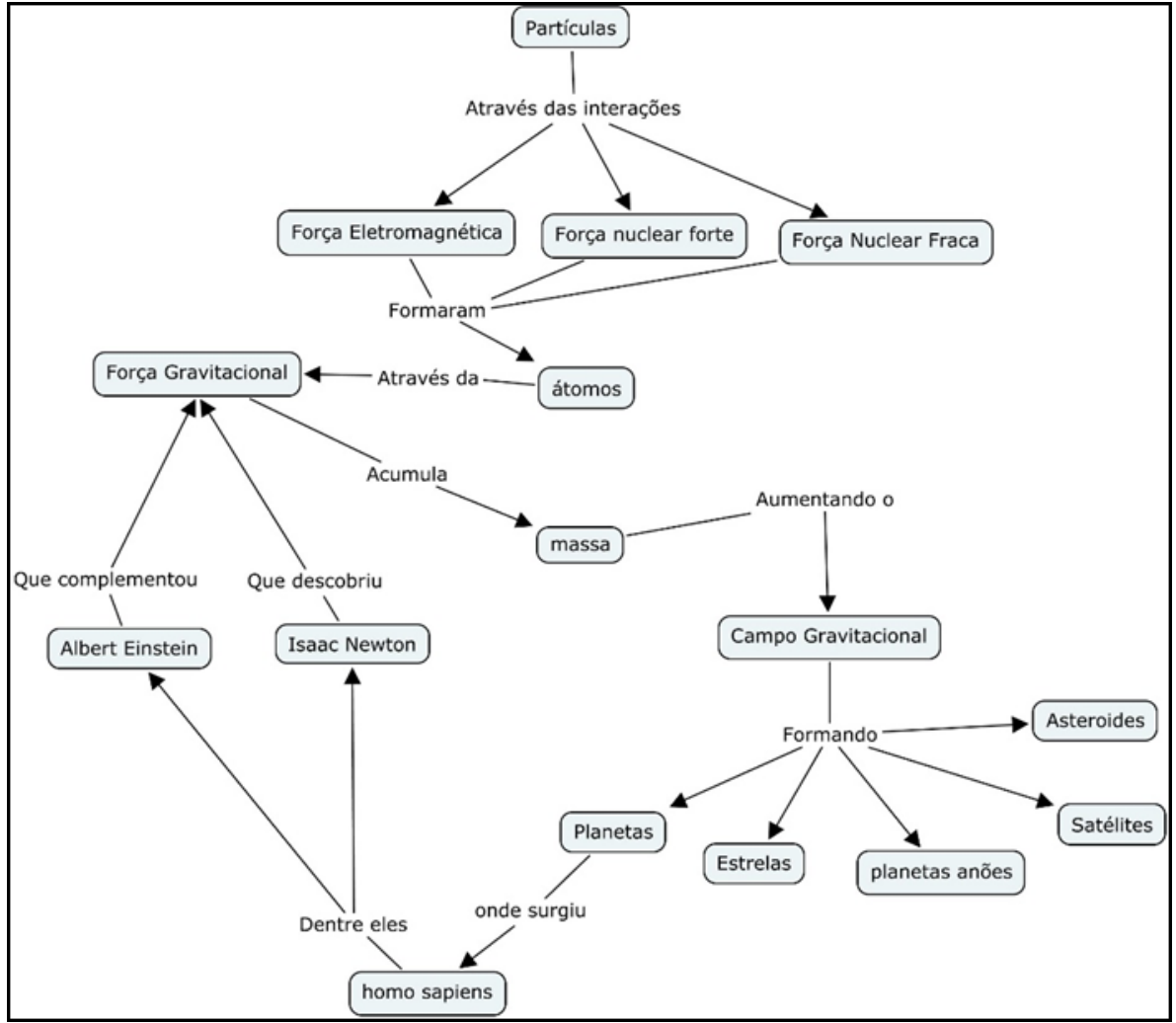

(b)

Figura 2: (a) Exemplo de ordenação das ações de uma aula baseada em exploração de conceitos prévios elaborada por um aluno do curso presencial; (b) Mapa conceitual de um conteúdo de mecânica elaborado no plano de aula do mesmo aluno. 
A partir da figura acima, podemos observar que o aluno vai apresentando de uma forma opinativa e informal o que compreende sobre as ações do professor em uma atividade de exploração de conceitos prévios. Apresenta as questões que faria a seus alunos e como responderia às exposições de suas concepções prévias. Em geral, a sequência de abordagem segue o seguinte esquema: questões - espaço para discussão - novas questões - conclusão, que foi seguida intuitivamente pelos alunos de ambas as modalidades de curso. Ou seja, nesta atividade também houve uma aproximação entre as formas de abordagem de aula propostas pelos alunos das licenciaturas presencial e EaD. Isso se deve principalmente a uma uniformização das aulas da disciplina, fruto do planejamento conjunto entre os docentes.

Ressaltamos que essa uniformidade não deve ser compreendida como padronização, mas como uma aproximação entre os aspectos formativos das disciplinas de ambos os cursos. Ela foi observada na grande maioria das atividades e trabalhos desenvolvidos pelos licenciandos, o que nos permite supor que a possibilidade do desenvolvimento de disciplinas em conjunto entre docentes das licenciaturas em Física em modalidades diferentes pode surtir efeitos positivos quanto à formação dos alunos para a prática docente. Assim, entendemos que o planejamento conjunto deve ser um caminho a ser compartilhado entre docentes de diversas licenciaturas a fim de tornar possível uma aproximação entre as competências desenvolvidas na formação de professores em diferentes modalidades de curso.

\section{CONSIDERAÇÕES FINAIS}

A pesquisa aqui relatada analisou as construções dos alunos de dois cursos de licenciatura em Física sobre um determinado tema de Mecânica a partir de uma abordagem planejada em conjunto entre professores de uma mesma disciplina nas modalidades presencial e EaD. Um ponto a ser destacado nestas análises é a viabilidade de se desenvolver atividades conjuntas para disciplinas de cursos que apresentam diferentes modalidades, como no exemplo deste trabalho. Essa consideração está pautada no fato de a modalidade EaD ainda ser relativamente nova e necessitar de estudos e propostas que visem a reflexão sobre a qualidade da formação de professores, ao passo que a forma presencial já está bem estabelecida.

A partir de uma abordagem planejada na disciplina de Prática de Ensino de Física, procurou-se desenvolver uma sequência de aulas e debater as formas de introdução desse tema na disciplina, considerando suas especificidades, com a intenção de fornecer a mesma formação aos alunos desses cursos, além de leválos a desenvolver as mesmas habilidades.

A leitura e análise das atividades desenvolvidas pelos licenciandos, representadas neste trabalho mostram que eles elaboram e resolvem problemas a partir de uma mesma recomendação teórica, a saber, a das leituras e discussões desenvolvidas em ambas as disciplinas. Percebemos que as situações e formas de resolução são influenciadas pelo contexto da aula, diferenciando-se entre as duas modalidades. Todavia, ainda assim os licenciandos de ambos os cursos constroem problemas e os resolvem a partir dos mesmos princípios norteadores e com a mesma qualidade. 
Com este trabalho pretendemos apresentar alguns indícios da necessidade de trabalho conjunto para o planejamento de disciplinas e da atuação dos docentes nos cursos de licenciatura em Física nas modalidades presencial e EaD, assim como a discussão sobre a necessidade de concatenar de forma teórica e prática as formações nas duas modalidades de licenciatura em Física. 


\title{
Contributions of a joint planning among the presential and online courses models in the constitution of a discipline of physics teaching practice
}

\begin{abstract}
We present and discuss the possibilities for formation arising from a planned made together to build a discipline of Physics Teaching Practice in two different degree courses in Physics, in class and at distance modalities. From the analysis of the plantings of two teachers and of the works and activities built by students of these disciplines, it was possible to present a systematization of important characteristics relating to both aspects of teacher of Physics of the possibilities of joint planning between teachers of the same discipline. The analyzes show an initial gap among the ways of content approach of these disciplines in the two types of degree in Physics and, then, we described a way for the approximating the contents and methodologies, opening the possibility of discussion of the potential of joint planning disciplines in undergraduate education.
\end{abstract}

KEYWORDS: Joint Planning. Initial Formation in Physics. Initial Formation in Physics at distance. Physics Teaching Practice. 


\section{REFERÊNCIAS}

BORTOLETTO, A.; Formação Continuada de Professores: A Experiência de uma Temática Sociocientífica na Perspectiva do Agir Comunicativo. Faculdade de Ciência - Universidade Estadual Paulista "Julio de Mesquisa Filho". Bauru, p. 237. 2013. Tese de doutorado.

CARR, W.; KEMMIS, S. Teoría crítica de la enseñanza: la investigación-acción en la formación del professorado. Barcelona: Martínez Roca, 1988.

CLEMENT, L.; TERRAZZAN, E.A.; NASCIMENTO, T. B. Resolução de problemas no ensino de física baseado numa abordagem investigativa. Atas do IV Encontro Nacional de Pesquisas em Educação em Ciências. Bauru, 2003.

CUNHA, S. L. S. Reflexões sobre o EaD no Ensino de Física. Revista Brasileira de Ensino de Física, São Paulo, v. 28, n. 2, p. 151-153, 2006.

DELIZOICOV, D. Problemas e problematizações. In: PIETROCOLA, M. (Org.) Ensino de Física: conteúdo, metodologia e epistemologia em uma concepção integradora. Florianópolis: Editora da UFSC, 2002. p. 125- 150

FERNANDES, G. W. R.; QUARTIERO, E. M.; ANGOTTI, J. A. P. Formação de professores de física a distância: em busca de novas práticas. Atas do VI ENPEC. Campinas: 2011. p. 285-297.

FLORES, C. R. et al. Avaliação de cursos de licenciatura em física e matemática a distância: um modelo possível. Avaliação, Campinas, 15, n. 2, 2010. 181-200.

FREITAS, Z. L. Um projeto de interação universidade-escola como espaço formativo para a docência do professor universitário. Faculdade de Ciência Universidade Estadual Paulista "Julio de Mesquisa Filho". Bauru, p. 140. 2008. Tese de doutorado.

HABERMAS, J. Teoria do agir comunicativo 1: Racionalidade da ação e racionalização social. Tradução de Paulo Astor Soethe. 1. ed. São Paulo: Martins Fontes, 2012. 704 p.

HABERMAS, J. Teoria do Agir Comunicativo 2: Sobre a crítica da razão funcionalista. Tradução de Flávio Bueno Siebeneichler. São Paulo: Martins Fontes, 2012. $811 \mathrm{p}$. 
NEVES da SILVA, J. R. As interações entre docentes da licenciatura em física em grupos de planejamento conjunto: uma análise a partir da teoria do agir comunicativo. 2014. 505 f. Tese (Doutorado em Educação para a Ciência) Faculdade de Ciências - Universidade Estadual Paulista, Bauru, SP.

ORQUIZA DE CARVALHO, L. M. A educação de professores como formação cultural: a constituição de um espaço de formação na interface entre a universidade e a escola. Universidade Estadual Paulista "Julio de Mesquita Filho". Ilha Solteira, p. 263. 2005. Tese de Livre Docência.

PEDUZZI, L.O.Q. Sobre a resolução de problemas no ensino de física. Caderno Catarinense de Ensino de Física, v.14, n. 3: p.229-253, dez.1997.

PENNA-FIRME, A. B. Ensino de Física: Da Resolução de Problemas à Formulação de Questões. Atas do V Encontro Nacional de Pesquisas em Educação em Ciências. Bauru, 2005.

QUEIRÓS, W. P. D. A articulação das cultutas humanistica e científica por meio do estudo histórico-sociocultural dos trabalhos de James Prescout Joule: contribuições para uma formação de professores universitários de perspectiva transformadora. Universidade Estadual Paulista "Julio de Mesquita Filho". Bauru. 2012.

SHULMAN, L. S. Those Who Understand: Knowledge Growth in Teaching. Educational Researcher, v. 15, n. 2, p. 4-14, Fevereiro 1986.

SOUZA, C. S. B. N. D. Licenciaturas na modalidade a distância e o desafio da qualidade: uma proposta de indicadores para aferir qualidade nos cursos de física, química, biologia e matemática. Pontifícia Universidade Católica do rio Grande do Sul. Porto Alegre, p. 186. 2009.

WEBER, M. Ensaios de sociologia. Rio de Janeiro: Zahar Editores, 1979. 
Recebido: 05 de mai. de 2015

Aprovado: 20 de mar. de 2016.

DOI: $10.3895 /$ rbect.v9n1.2996

Como citar:

SILVA, J. R. N. et al. Contribuições de um planejamento conjunto entre as modalidades presencial e a distância na constituição de uma disciplina de prática de ensino de física. Revista Brasileira de Ensino de

Ciência e Tecnologia, v. 9, n. 1, p. 1-25, jan./abr. 2016. Disponível em:

$<$ https://periodicos.utfpr.edu.br/rbect/article/view/2996>. Acesso em: xxx.

Correspondência:

João Ricardo Neves da Silva

Av. BPS, 1303, Bairro Pinheirinho, CEP: 37500-903

Agenor Pina da Silva

Av. BPS, 1303, Bairro Pinheirinho, CEP: 37500-903

Camila Cardoso Moreira

Av. BPS, 1303, Bairro Pinheirinho, CEP: 37500-903

Joaquim Francisco Pereira

Av. BPS, 1303, Bairro Pinheirinho, CEP: 37500-903

Direito autoral: Este artigo está licenciado sob os termos da Licença Creative Commons-Atribuição 4.0

Internacional.

Página | 25 